\title{
Docência e trabalhos de campo nas disciplinas Ciência do Sistema Terra I e II da UNICAMP
}

\author{
Celso Dal Ré Carneiro ${ }^{1}$, Pedro Wagner Gonçalves ${ }^{1}$, Carlos Alberto Lobão da Silveira Cunha ${ }^{1}$ \& \\ Oscar Braz Mendonza Negrão ${ }^{1}$
}

\begin{abstract}
Resumo Em disciplinas geológicas introdutórias é possível construir um currículo que contemple traços essenciais do funcionamento do planeta e de sua longa história. Isso requer clara explicitação dos objetivos das atividades para facilitar a aproximação dos alunos com os temas mais relevantes. As disciplinas Ciência do Sistema Terra I e II desenvolvem conteúdos geológicos e abordam a natureza e modos de construção do conhecimento geológico. Ao longo de dez anos contínuos de trabalhos de campo, realizados na forma de viagens curtas, houve sensível evolução quanto às narrativas desenvolvidas. Os roteiros e pontos de visita são selecionados e organizados de acordo com critérios educacionais. O presente artigo discute a necessidade do planejamento detalhado dos trabalhos de campo, em função das concepções didáticas e do enfoque metodológico. A aplicação dos temas, em ao menos três viagens por ano, permite que os alunos: (1) construam conhecimentos a partir de observação e interpretação de processos naturais e respectivos produtos; (2) comparem suas próprias idéias com as formuladas por colegas e professores; (3) compreendam que a ciência é produzida mediante formulação de teorias, explicações e hipóteses. Desse modo, estimula-se o aluno a conquistar seu próprio aprendizado, individual ou de modo coletivo, cumprindo os professores o papel de facilitadores da aprendizagem.
\end{abstract}

Palavras-chave: Ensino de geociências, Geologia Introdutória, atividades de campo, educação ambiental, currículo, ensino superior.

\begin{abstract}
Teaching and fieldwork in the Earth System Science disciplines at the State University of Campinas. The curriculum of introductory geological disciplines should focus on characteristics of the operation and long history of the planet. This requires the objectives of the activities to be clearly defined, and the most relevant themes to be highlighted. Earth System Science I and II disciplines develop geologic contents in the Geology and Geography undergraduate courses of the State University of Campinas. They must approach the nature and ways of production of geologic knowledge, therefore allowing the student to understand the planet. Fieldwork assumes a basic role. A detailed planning of short field trips along two semesters have defined three successive themes to be developed in the field: (a) geology of sand quarries and present-day sedimentation processes; (b) Permian-Carboniferous glaciations at the Parana basin; (c) rock cycle and Geologic Time. The fieldtrip framework stimulate the students: (1) to construct knowledge from observation and interpretation of geological processes and products; (2) to compare their own ideas with those formulated by colleagues and teachers; (3) to understand that science production requires formulation of theories, explanations and hypothesis. Fieldwork helps students to develop, individually or collectively, their proper learning, actively supported by the teachers.
\end{abstract}

Keywords: Geosciences teaching, Introductory Geology, fieldwork, environmental education, curriculum, undergraduate teaching.

INTRODUÇÃO A experiência docente acumulada em uma década de oferecimento das disciplinas geológicas introdutórias Ciência do Sistema Terra I e II, na Universidade Estadual de Campinas (Unicamp), permite explorar e discutir o significado dos trabalhos de campo na formação superior de geógrafos e geólogos. A análise foi iniciada por ocasião dos eventos $1^{\circ} \mathrm{Sim}-$ pósio de Pesquisa em Ensino e História de Ciências da Terra, e III Simpósio Nacional sobre Ensino de Geologia no Brasil, realizados em Campinas, entre 4 e 8 de setembro de 2007, quando se descreveram as disciplinas e se analisaram os trabalhos de campo, a evolução do planejamento, as mudanças nas concepções e algumas alterações metodológicas (Carneiro et al. 2007). A equipe básica pouco se alterou com o tempo. Houve esforço permanente de aprimorar os roteiros de campo, incorporando-se novos experimentos e orientações acerca dos raciocínios exigidos.

Pretende-se aqui aprofundar o exame do papel desempenhado pelos trabalhos de campo. Pela importância desse conhecimento para a educação integral das pessoas, é essencial formular novos programas interdisciplinares baseados em Geociências (Cuello Gijón 1988) e difundir amplamente as Ciências da Terra em

1 - Depto. Geociências Aplicadas ao Ensino, Instituto de Geociências, Universidade Estadual de Campinas, UNICAMP, Campinas (SP), Brasil. E-mail: cedrec@ige.unicamp.br 
cursos superiores e na educação básica (Domingo \& Sequeiros 1998, Fyfe 1997). Em todos esses setores o campo assume papel relevante, tanto na formação de conceitos, como na contextualização do conhecimento.

A análise parece ser útil para colocar em pauta o papel das disciplinas de geologia introdutória para formar uma visão integrada do desenvolvimento da ciência geológica. Um objetivo específico deste artigo é levantar requisitos específicos das atividades de campo que possam definir diferentes orientações ao trabalho de campo em cursos similares. Na experiência da Unicamp, as turmas dos períodos diurno e noturno fazem viagens simultâneas aos sábados, o que elimina um obstáculo para o campo.

POSIÇÃO DAS DISCIPLINAS NA GRADE CURRICULAR No curso Ciências da Terra os estudantes optam, ao final de um núcleo comum de disciplinas, entre carreiras de bacharelado em Geologia, bacharelado ou licenciatura em Geografia. Atualmente, a escolha ocorre ao final do primeiro ano. As disciplinas devem pois fornecer a fundamentação teórico-prática de Geociências (que entendemos como sinônimo de Ciências da Terra) às duas carreiras (Gonçalves et al. 2000, Gonçalves e Carneiro 2003, Carneiro et al. 2005, Carneiro e Gonçalves 2006). No núcleo comum somente as disciplinas Trabalho de Campo e Introdução ao Sensoriamento Remoto abordam conteúdos geológicos, mas o tratamento dado nessas disciplinas é marginal, porque tratam de conjunto mais amplo de conhecimentos, no qual Geologia está presente.

Nos primeiros anos de oferta do curso havia intenção expressa de conduzir os alunos a relacionar os estudos de sistema Terra e os de sistema mundo (Carneiro et al. 2005a), notadamente no segundo semestre (Ciência do Sistema Terra II). O aperfeiçoamento da experiência educativa levou à divisão de funções e conteúdos de disciplinas. As disciplinas Ciência do Sistema Terra I e II foram reduzidas em escopo - a carga horária total reduziu-se de $90+45 \mathrm{~h}=135$ horas para $60+60 \mathrm{~h}=$ 120 horas - mas elas concentraram-se no tratamento de conteúdos geológicos (Carneiro et al. 2007). Criaramse duas de caráter puramente geográfico: Ciência do Sistema Mundo I e II. Redimensionaram-se as cargas horárias, porque conteúdos de Geografia foram retirados das ementas de Ciência do Sistema Terra. Carneiro et al. (2007) apresentam as mudanças nas ementas devidas ao processo de reformulação curricular.

A abordagem didática busca enxergar a Terra como um todo, na medida em que são focalizadas as múltiplas inter-relações espaço-temporais das diferentes esferas e se procura fornecer aos alunos uma visão integrada de: (a) composição e principais mecanismos de funcionamento das esferas terrestres: geosfera, hidrosfera, atmosfera, biosfera, antroposfera e noosfera; (b) conhecimento contemporâneo sobre interações no ambiente terrestre; (c) evolução das interações ambientais na história da Terra; (d) efeitos das atividades humanas e sociais na superfície da Terra, a partir de um foco interdisciplinar; (e) conexões entre tecnosfera e ecosfera.
NARRATIVAS DE CAMPO Podemos tomar como referência a idéia de que todo trabalho de campo constitui uma narrativa, selecionada e organizada pelo professor, de acordo com critérios educacionais e segundo os objetivos pretendidos nas atividades, para trazer os estudantes mais próximos de uma realidade que deve ser estudada e investigada. A ênfase em aspectos metodológicos (Praia 1996) é crítica na construção dos estudos da Terra por Ciência do Sistema Terra. Por esse motivo, discutimos a seguir algumas contribuições relevantes e referimos de que forma os conceitos são inseridos no programa.

A questão do Tempo Geológico é desenvolvida desde os problemas metodológicos de interpretação de eventos nos quais apenas é possível operar somente com tempo relativo, até chegar às divisões da escala absoluta do Tempo Geológico (Press et al. 2006), quando os alunos tomam contato com os métodos de datação de rochas e materiais naturais (Carneiro et al. 2005b). $\mathrm{Na}$ abordagem se atribui grande importância ao método histórico-comparativo e ao princípio do Atualismo (Carneiro et al. 1994), uma vez que, para interpretar as características naturais, seus eventos e ciclos, um pesquisador deve exercitar procedimentos típicos de ciências históricas (pensamento analógico, indutivo, dedutivo e multifatorial).

$\mathrm{O}$ entendimento dos processos naturais assume, cada vez mais, caráter interdisciplinar (King 1990). Desse modo, para compreender fatos relativos às geociências os profissionais precisam expandir sua capacitação para tratar problemas complexos e multidisciplinares. Por outro lado, a interpretação dos fenômenos geológicos depende diretamente da qualidade e grau de detalhe das informações disponíveis. Ao se enfatizar a dependência entre registros disponíveis e estudos relacionados à história evolutiva, considerando sobretudo sua longa duração (Van Loon 1999, Sequeiros et al. 1997) pode-se desenvolver a idéia de processo histórico-geológico.

No campo, os alunos devem aprender mediante participação ativa dos professores, cuja função é a de facilitadores da aprendizagem. As práticas de ensino buscam desenvolver nos alunos a criatividade, a habilidade de observar e compreender os processos naturais, a capacidade de analisar e integrar diferentes tipos de informação e habilidades de pensamento cíclico. Os estudantes e professores realizam conexões mentais para interpretar o registro gravado nas rochas.

As atividades práticas e de campo desempenham papel central no desenvolvimento de habilidades de observação e interpretação de fenômenos ligados às Ciências da Terra (Carneiro et al. 2007). As atividades de campo se inserem em uma cadeia de atividades das unidades de fundamentos metodológicos da Geologia e geosfera (Quadro 1) na qual diferentes papéis didáticos (Compiani e Carneiro 1993) podem ser fixados para as atividades de campo. São dois dias de campo no primeiro semestre e um dia no segundo semestre. Em 1998 houve quatro dias integrais de campo, sendo um dia no primeiro semestre, e uma viagem mais longa no segundo. Nos anos seguintes, uma menor quantidade 
Quadro 1 - Seqüência de atividades desenvolvidas na unidade Geosfera.

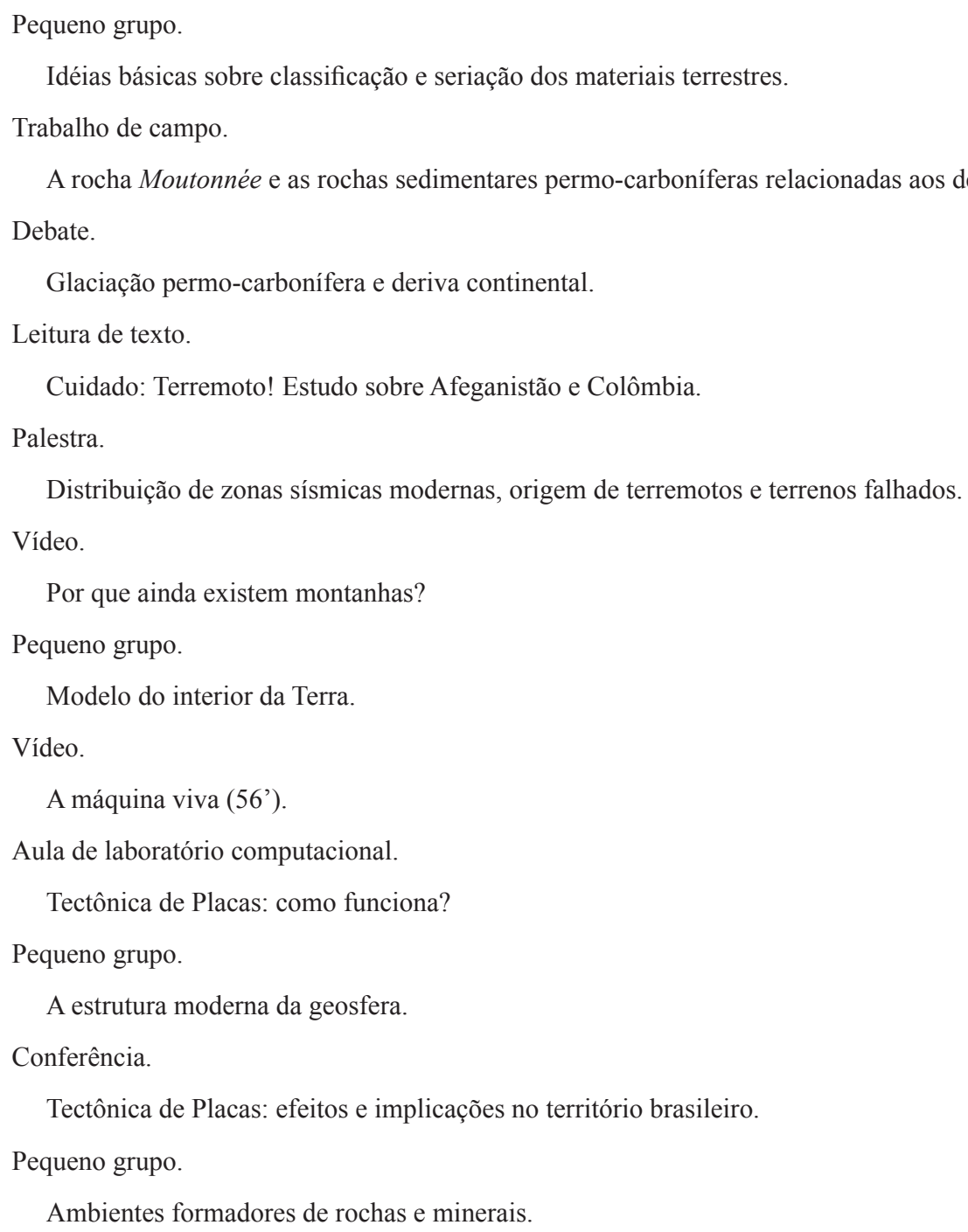

de dias de campo foi tomando forma, associada a excursões de um dia (duas no primeiro semestre e uma no segundo).

Um dos objetivos didáticos é buscar fazer o trabalho dos alunos exercitar o típico raciocínio geológico. A explicitação clara dos objetivos das atividades de campo é condição para que, mesmo fazendo alterações na escolha dos locais a serem visitados em campo, os docentes tornem progressivo o ensino-aprendizagem. Os roteiros das viagens de campo mais bem-sucedidos foram repetidos, enquanto outros tiveram de ser bastante modificados, para melhorar o aproveitamento dos alunos. Os resultados, muitas vezes, funcionam como referencial para futuras atividades dos estudantes na própria disciplina.

As viagens modificaram-se primeiramente quanto às áreas visitadas (Fig. 1 e Tab. 1), mas também quanto aos objetivos estabelecidos (Tab. 2). Os objetivos gerais e específicos do conjunto de atividades de campo definem uma série de aptidões a serem desenvolvidas pelos alunos, após realizar as atividades pro- postas. A tabela 2 simplifica a descrição subseqüente, para não repetir objetivos similares.

Os relatórios de campo constituem o produto das atividades e refletem em parte as concepções adotadas. Diferentes áreas geográficas, com seus respectivos ambientes geológicos pretéritos, podem ser aproveitados nessa busca por uma construção de explanações históricas do passado da Terra. Isso não significa que uma mesma área geográfica não possa suprir o alcance de conjuntos determinados - e distintos - de objetivos, mas que se pode explorar com maior intensidade as características de um dado local e focalizar o olhar dos estudantes em aspectos que estão, ali, mais bem representados do que em outros pontos. Neste artigo não se incluiu a avaliação dos alunos, que constitui outro elemento essencial.

Regiões visitadas em campo Por se tratar de área limítrofe entre domínios de embasamento cristalino e da Bacia do Paraná, a região de Campinas favorece estudos de campo. Visitam-se ali, em roteiros curtos, ocorrências dos três principais tipos de gênese de rochas: 
Tabela 1 - Localidades visitadas em campo.

\begin{tabular}{|c|c|c|c|}
\hline Intervalo & \multicolumn{2}{|c|}{ Ciência do Sistema Terra I } & Ciência do Sistema Terra II \\
\hline 1998 & \multicolumn{2}{|c|}{ Arredores de Campinas } & Caraguatatuba (3 dias) \\
\hline 1999-2002 & Itaquaquecetuba & \multirow{4}{*}{ Salto e Itu } & \multirow{4}{*}{$\begin{array}{c}\text { Perus, Jaraguá e arredores de } \\
\text { São Paulo }\end{array}$} \\
\hline $2002-2003$ & Jaguariúna & & \\
\hline 2004-2007 & Jacareí & & \\
\hline 2008 & Itaquaquecetuba & & \\
\hline
\end{tabular}

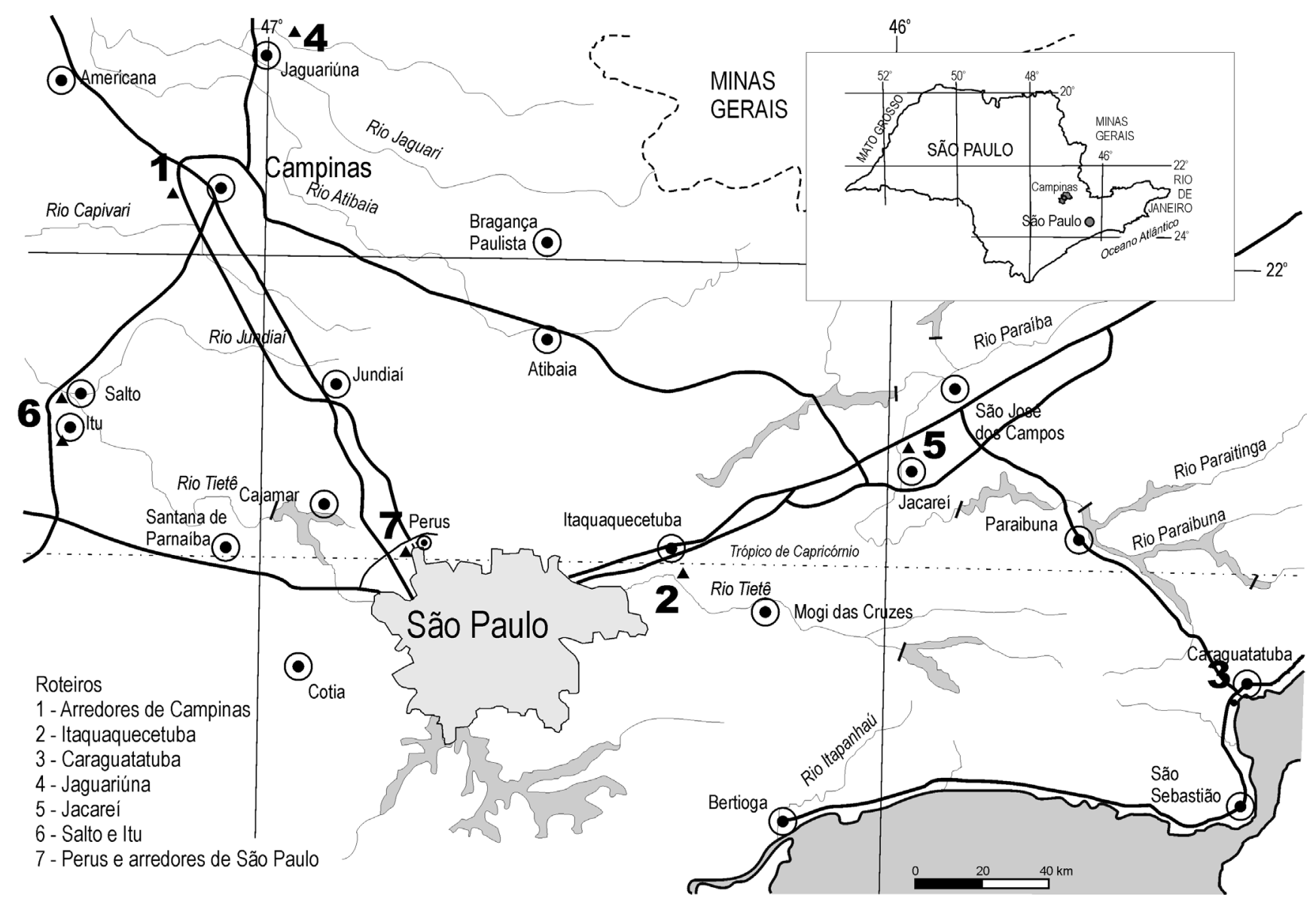

Figura 1 - Mapa de localização das áreas visitadas em campo.

magmáticas, metamórficas e sedimentares. As idades variam desde o Proterozóico e o Paleozóico até unidades geológicas recentes. A borda da Bacia do Paraná na região periférica entre Sorocaba, Salto, Itu, Indaiatuba e Campinas é ocupada por um pacote de camadas areno-silto-argilosas de idade permo-carbonífera que Washburne (1930) reuniu na Série Itararé, posteriormente considerada como um subgrupo do Grupo Tubarão (Mendes 1962 apud Mezzalira 1981). Propostas de subdivisão estratigráfica do Subgrupo Itararé tiveram pouco êxito devido à falta de continuidade lateral dos pacotes rochosos, ausência de camadas-guia ou limites claros entre formações (Soares et al. 1977). Gama Jr. et al. (1992a) assinalam a importância dos fluxos gravitacionais subaqüosos que realizaram retrabalhamento de tilitos, dando origem a fácies de ressedimentação em ambientes peri-glaciais.

Na região de Campinas-Indaiatuba-Moji Guaçu afloram ainda corpos tabulares concordantes de diabásio, originados por intrusões contemporâneas aos derrames de lava da Fm. Serra Geral (Eocretáceo), dispostas aproximadamente na zona de contato entre rochas do Subgrupo Itararé e o embasamento cristalino, formado por rochas paleoproterozóicas do Complexo Amparo, que reúne diversos tipos de gnaisses, migmatitos, xistos e anfibolitos, atravessados por potentes intrusões 
Tabela 2 - Objetivos de atividades de campo, desde a primeira, realizada nos arredores de Campinas.

\begin{tabular}{|c|c|}
\hline & etivos Gerais \\
\hline & alunos, após realizar as atividades propostas, devem estar aptos a: \\
\hline 1) & Reconhecer as principais rochas presentes na região e algumas espécies de minerais. \\
\hline 2) & Reconhecer a importância da escala na descrição de corpos naturais e elaboração de modelos explicativos. \\
\hline 3) & Discutir as noções de homogeneidade e heterogeneidade de corpos naturais. \\
\hline 4) & Aplicar as noções de superposição, interseção e correlação de estruturas. \\
\hline 5) & Reconhecer a possibilidade de reconstruir a história geológica da região percorrida. \\
\hline 6) & Correlacionar, por analogia, diferentes corpos rochosos. \\
\hline & Elaborar hipóteses sobre a origem das rochas encontradas. \\
\hline
\end{tabular}

\begin{tabular}{|c|c|c|}
\hline \multicolumn{3}{|l|}{ Objetivos Específicos } \\
\hline $\begin{array}{l}\text { Jaguariúna, Jacareí ou } \\
\text { Itaquaquecetuba }\end{array}$ & Campinas a Caraguatatuba & $\begin{array}{l}\text { Perus, Jaraguá e arredores de São } \\
\text { Paulo }\end{array}$ \\
\hline $\begin{array}{l}\text { Correlacionar, por analogia, } \\
\text { registros de processos atuais com } \\
\text { estruturas de corpos rochosos } \\
\text { antigos. }\end{array}$ & $\begin{array}{l}\text { Reconhecer evidências de processos } \\
\text { evolutivos do relevo do interior } \\
\text { continental e costeiro. }\end{array}$ & $\begin{array}{l}\text { Correlacionar produtos da decomposição } \\
\text { de rochas, em diferentes estágios de } \\
\text { intemperismo. }\end{array}$ \\
\hline \multirow[t]{4}{*}{$\begin{array}{l}\text { Aplicar classificação de } \\
\text { sedimentos, associando-a } \\
\text { às quantidades de energia } \\
\text { envolvidas no transporte. }\end{array}$} & $\begin{array}{l}\text { Exercitar a observação da paisagem } \\
\text { humanizada, registrando as } \\
\text { características visíveis da paisagem } \\
\text { e sua funcionalidade. }\end{array}$ & $\begin{array}{l}\text { Reconhecer algumas espécies minerais, } \\
\text { como feldspato, quartzo, turmalina, } \\
\text { granada, moscovita, biotita e sillimanita. }\end{array}$ \\
\hline & $\begin{array}{l}\text { Reconhecer as incompatibilidades } \\
\text { entre uso e ocupação do solo e a } \\
\text { dinâmica natural. }\end{array}$ & $\begin{array}{l}\text { Compreender as relações entre escalas de } \\
\text { espaço e de tempo nas reconstruções de } \\
\text { história geológica. }\end{array}$ \\
\hline & & $\begin{array}{l}\text { Compreender a denudação dos continentes } \\
\text { como parte integrante do ciclo das rochas. }\end{array}$ \\
\hline & & $\begin{array}{l}\text { Elaborar hipóteses sobre a posição das } \\
\text { rochas encontradas no ciclo das rochas. }\end{array}$ \\
\hline
\end{tabular}

graníticas e pegmatíticas neoproterozóicas. Na região de Sorocaba-Salto-Itu o embasamento é formado por rochas gnáissicas antigas e supracrustais (neoproterozóicas) do Grupo São Roque. O conjunto é atravessado por granitos dos batólitos de Itu e Sorocaba (CambroOrdoviciano). São filitos, quartzitos, metarenitos, xistos e calcários, e alguns termos subordinados. Valores neoproterozóicos obtidos em datações de rochas granitóides da região permitem relacionar o magmatismo ao final do Ciclo Brasiliano (Almeida 1967).

ARREDORES DE CAMPINAS Na primeira edição de Ciência do Sistema Terra I, em 1998, a atividade de campo focalizou a história geológica da região de Campinas e arredores, envolvendo sete afloramentos. $\mathrm{O}$ quadro 2 reproduz a seqüência de passos sugeridos no roteiro para o primeiro ponto visitado da série. $\mathrm{O}$ roteiro deveria ajudar os alunos a reconhecer algumas características dos ambientes existentes na época em que as rochas se formaram. Amostragem e observações deveriam permitir a compreensão da história geológica da região e suas mudanças ambientais. As atividades deveriam levar o aluno a aprimorar sua capacidade de observação, localização espacial e representação de feições naturais, além de reconhecer a natureza litológica e identificar feições estruturais simples das unidades visitadas (Tab. 2).

Particularmente em virtude do alto grau de dificuldade implícito na tarefa, a atividade não tornou a ser realizada na disciplina Ciência do Sistema Terra. Entendeu-se que alguns requisitos devem ser cumpridos antes de se propor aos alunos, em uma primeira visita de campo, tarefas tão diversificadas. Os alunos tiveram grande dificuldade de descrever os tipos de rochas encontradas e interpretar a disposição espacial das unidades, as relações genéticas entre elas e construir uma história evolutiva.

Os itens indicados no quadro 2 obedecem uma orientação geral dada aos alunos (Tab. 3) de "hierarquia das observações de campo", adaptada de Bach y Plaza et al. (1988). 
Quadro 2 - Atividades previstas durante a visita ao primeiro ponto de campo, em 1998.

AFLORAMENTO 1. Rod. dos Bandeirantes - próximo a Viracopos e trevo da Rod. Santos Dumont

1. Junto com os colegas de seu grupo, procure situar este local no mapa rodoviário (escala 1:250 000).

2. A uma certa distância faça um esquema, no quadro a seguir, do afloramento rochoso. Seja preciso; observe e indique a escala. Use uma legenda para indicar os materiais descritos. Na descrição você pode usar os seguintes critérios: cor, granulometria (tamanho dos grãos), textura (feições geométricas de pequenas dimensões), estruturas e outros critérios que considerar relevantes.

3. Quantos tipos de materiais diferentes você descreveu? Quais foram as características distintivas entre eles?

4. Compare seu esquema com o de seus colegas. Discuta com eles as diferenças ou semelhanças de um esquema para o outro.

5. Aproxime-se do afloramento. Procure fazer uma nova descrição de cada um dos materiais mostrados por seu esquema do ítem 2. (Faça pelo menos um esquema de uma área de cerca de $1 \mathrm{~m}^{2}$ ).

6. Discuta com os colegas de seu grupo semelhanças e diferenças relacionadas à mudança de escala de observação.

7. Tendo clareza sobre os materiais presentes, formule hipóteses explicativas sobre a gênese dos materiais presentes no afloramento. Leve em conta as possíveis condições energéticas dominantes na época de formação desses materiais.

8. De posse de suas conclusões do item anterior, classifique a rocha quanto à gênese.

9. Que critérios você utilizou para saber qual é o tipo da rocha?

Tabela 3 - Orientação sobre hierarquia das observações de campo (adaptada de Bach y Plaza et al. 1988).

\begin{tabular}{|c|c|c|c|}
\hline \multicolumn{4}{|c|}{ Hierarquia das observações de campo } \\
\hline & Etapas & Atividades & Recursos \\
\hline 1 & $\begin{array}{l}\text { Situação dentro de grandes } \\
\text { unidades geológicas e de relevo }\end{array}$ & Visão panorâmica da paisagem & $\begin{array}{l}\text { Utilizar elementos } \\
\text { descritivos: }\end{array}$ \\
\hline 2 & $\begin{array}{l}\text { Situação do afloramento no } \\
\text { contexto da paisagem próxima }\end{array}$ & $\begin{array}{l}\text { Procurar obter conhecimento } \\
\text { dos elementos morfológicos da } \\
\text { paisagem para isolar unidades do } \\
\text { relevo }\end{array}$ & $\begin{array}{l}\text { GRÁFICOS } \\
\text { Escala } \\
\text { Símbolos }\end{array}$ \\
\hline 3 & $\begin{array}{l}\text { Visão de conjunto do } \\
\text { afloramento }\end{array}$ & $\begin{array}{l}\text { Observação do afloramento à } \\
\text { distância. } \\
\text { Reconhecer: } \\
\text { - Estrutura e disposição dos } \\
\text { materiais }\end{array}$ & ESCRITOS \\
\hline 4 & $\begin{array}{l}\text { Estudo em detalhe do } \\
\text { afloramento }\end{array}$ & $\begin{array}{l}\text { Descrição e identificação genética } \\
\text { de cada unidade litológica }\end{array}$ & Terminologia \\
\hline 5 & Estudo de amostra de mão & $\begin{array}{l}\text { Classificação dos tipos de rochas } \\
\text { em função da identificação de } \\
\text { componentes: } \\
\text { - Textura } \\
\text { - Minerais e/ou } \\
\text { fósseis presentes } \\
\end{array}$ & \\
\hline 6 & $\begin{array}{l}\text { Elaboração de modelo } \\
\text { interpretativo do afloramento }\end{array}$ & Síntese de observações realizadas & \\
\hline 7 & $\begin{array}{l}\text { Síntese de todo o conjunto de } \\
\text { afloramentos e elaboração de } \\
\text { modelo global }\end{array}$ & & \\
\hline
\end{tabular}


CAMPINAS A CARAGUATATUBA A atividade de campo de Ciência do Sistema Terra II, em 1998, cobriu a seção entre Campinas e Caraguatatuba para observação de aspectos geológicos e geográficos. A porção do Planalto Atlântico entre Campinas e o litoral norte de São Paulo possui extrema variedade de feições geológicas e geomorfológicas, e um substrato de rochas deformadas, com arranjos estruturais complexos, submetidas a uma série de episódios erosivos, que deu origem a diversificado modelado do relevo.

As idades das unidades de rochas visitadas variam do Paleoproterozóico ao Pleistoceno. A formação sócio-espacial é diversificada e importante do pontode-vista estratégico. Localizada entre os dois principais pólos econômicos do país - São Paulo e Rio de Janeiro - apresenta grandes contrastes de ocupação. De um lado, plantações em curvas de nível, alternância de culturas, condomínios bem-planejados; de outro, explotação predatória de recursos naturais ou equívocos no uso do solo que provocaram mudanças profundas na paisagem. O domínio de Mata Atlântica reduziu-se a pequena parcela de sua extensão original. Reconhecem-se morros recobertos por vegetação de pasto, em uma zona antes florestada que sofreu as conseqüências de uma devastação promovida pela extração de lenha e lavoura do café; esta última adentrou o Estado de São Paulo pelo vale do Rio Paraíba do Sul. Salienta-se ainda a urbanização de porções de várzea do mesmo rio, onde cidades foram "plantadas" em terra fértil. São procedimentos geradores de problemas geológicos e ambientais.

Novamente considerou-se que as tarefas foram demasiadamente diversificadas. Durante a excursão foram visitados afloramentos e coletaram-se amostras de diversos tipos de rochas, algumas delas intemperizadas. Percorremos áreas sedimentares das bacias terciárias de Taubaté e São Paulo e da pequena mancha de acumulações presentes no vale do rio Jundiaí. As observações geológicas e geográficas, bem como as inter-relações de dados tiveram a finalidade de ajudar a compreender a história geológica da região e a evolução do relevo e a inserir nesse quadro as mudanças introduzidas pela ocupação humana.

ITAQUAQUECETUBA A atividade de campo da disciplina Ciência do Sistema Terra I, em 1999-2001, dedicou-se ao estudo da história geológica da região de Itaquaquecetuba, onde foi visitado um porto de areia geologicamente magnífico, no qual fôra definida a unidade litoestratigráfica homônima (Coimbra et al. 1983, Almeida et al. 1984). Na área podem ser observadas sucessivas camadas cortadas por falhas e juntas, bem como restos de materiais fossilizados e feições erosivas, além dos efeitos da ação humana. Situada à margem esquerda do Rio Tietê e bastante próxima a áreas de intensa urbanização, as exposições realmente impressionam o visitante pelas grandes dimensões. A atividade foi repetida em 2008, porque não houve o esgotamento previsto das reservas e a jazida continua a ser explotada.

As idades de rochas da região variam entre o
Paleógeno e o Pleistoceno (entre 65 e 2 Ma atrás). Na atividade buscou-se reconstruir os ambientes de sedimentação que existiram na época em que as rochas se formaram, como parte da compreensão da história geológica regional. Foram feitas experiências com sedimentos lançados em correntes de água, que poderiam ajudar os alunos a reconhecer algumas características dos processos sedimentares atuais. Os alunos foram convidados a observar quais intervalos granulométricos (tamanhos de grãos) poderiam ser transportados pela correnteza, o que lhes permitiu compreender e estabelecer, com certa facilidade, relações entre a capacidade de transporte da corrente (velocidade e quantidade de água) e o tamanho dos grãos transportados. A visita envolveu alguns pontos de afloramento de arenitos, conglomerados e sedimentos inconsolidados recentes (areias, cascalhos, siltes e argilas) para estabelecimento de relações simplificadas dos princípios da horizontalidade, da continuidade lateral, da correlação, da horizontalidade original dos estratos, da superposição e da interseção de estruturas observadas em sistemas de falhas.

No trabalho de campo em Itaquaquecetuba, os alunos tomaram contato também com explanações sobre os critérios de realização das operações de lavra e os diversos requisitos ambientais a serem obedecidos, além de conhecer em que consiste o tratamento da areia. Assinalou-se que os controles ambientais determinam que as atividades de extração sejam realizadas de um modo circunscrito à área de lavra, assemelhando-se a um sistema fechado, um conceito bem desenvolvido na disciplina.

As atividades perseguem a idéia de que os estudos geológicos da Terra são históricos e que toda transferência de informação no tempo necessita construir modelos e explicações aceitáveis pelo conhecimento científico do presente. Tal pressuposto teórico é realizado de forma simulada à medida que os registros pliocênicos e pleistocênicos são interpretados por meio de modelos formulados a partir de observações e interpretações de fenômenos atuais. A checagem da efetividade da metodologia de pesquisa adotada é feita depois da atividade de campo por meio de reflexão sobre as interpretações e representações feitas pelos alunos (debate da excursão e relatório da atividade).

SALTO E ITU Desde 1999 é realizada uma atividade de campo de Ciência do Sistema Terra I aos parques naturais de Itu e Salto (Rocha-Campos 2002a, 2002b). O primeiro está bem instalado nos amplos paredões e patamares da pedreira desativada de varvito, cuja origem tem sido relacionada a correntes de turbidez. Em Salto, a singular exposição da Rocha Moutonnée (Fig. 2) sobre granito exibe marcas profundas de lavra que prosseguiu até o início dos anos 1990, sem interrupção, desde quando os primeiros alertas sobre sua inestimável importância científica foram publicados (Almeida 1948).

Nas exposições de Itu, as rochas do Subgrupo Itararé (Permo-Carbonífero) apresentam-se como delicadas camadas de espessuras submilimétricas a milimétricas, ondulações e laminações, seixos pingados, mar- 


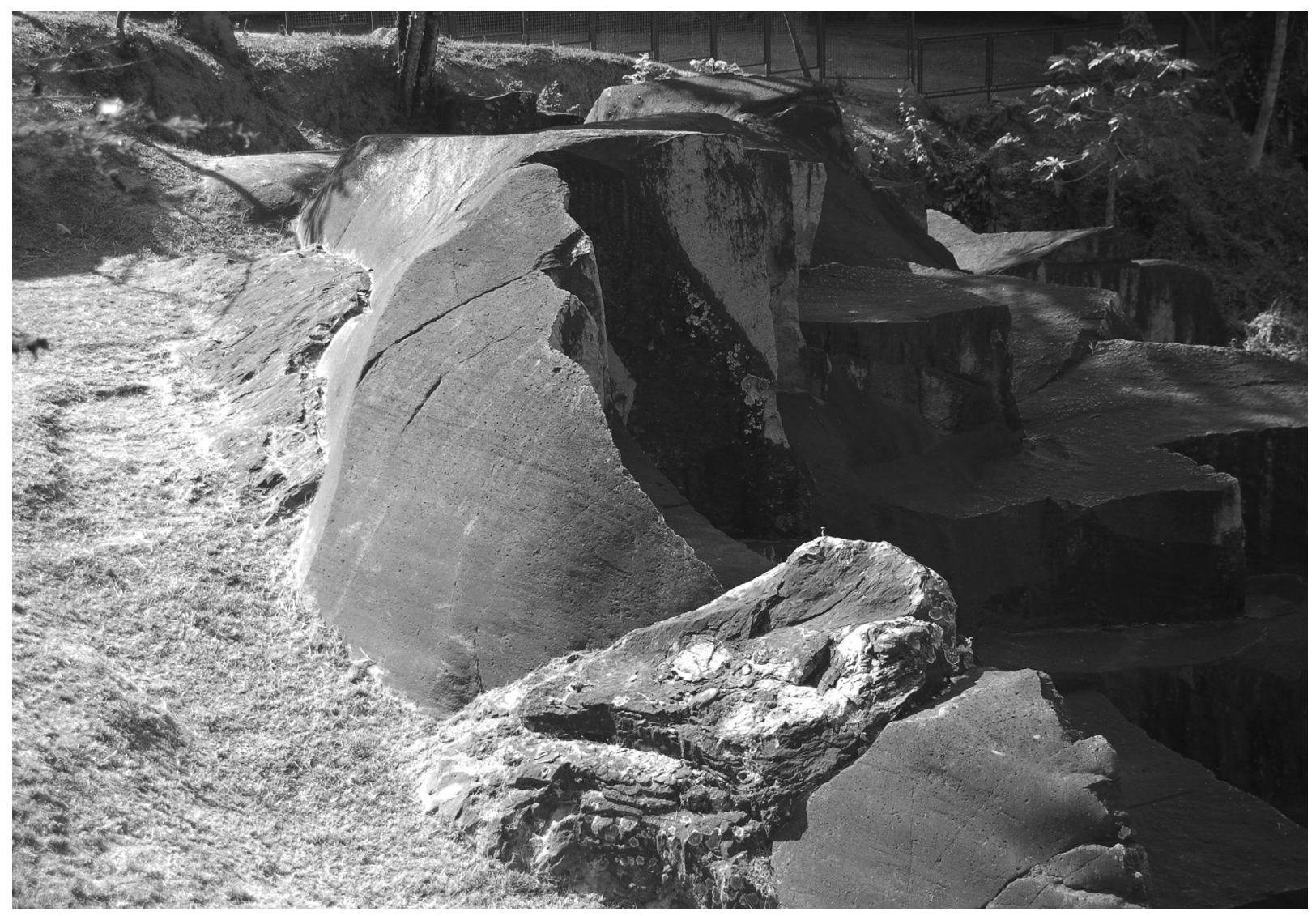

Figura 2 - Aspecto atual do Parque da Rocha Moutonnée em Salto, bastante danificada pela lavra de granito. Apenas uma face restrita da antiga exposição ficou intacta. Sugere-se comparar esta foto com as ilustrações de Almeida (1948).

cas fósseis deixadas por poliquetos, seixos facetados e alguns estriados. Em Salto, além das estrias superficiais devidas ao arraste de materiais na base do gelo no granito de Itu, há inúmeras feições de arrancamento de minerais e pedaços da rocha, além de restritos depósitos de tilitos junto ao granito.

PERUS E ARREDORES DE SÃO PAULO A atividade de campo de Ciência do Sistema Terra II em 1999 - que vem sendo realizada todos os anos desde então - focalizou o tema "ciclo das rochas e história geológica de São Paulo", aproveitando pedreiras de granito e exposições do Rodoanel Metropolitano Mario Covas na Região de Perus, na parte noroeste da cidade de São Paulo. Podem ser encontrados ali os diferentes tipos de gênese de rochas: magmáticas e metamórficas. As idades situam-se entre o Neoproterozóico e o CambroOrdoviciano. A área constitui um dos primeiros sítios de mineração da cidade, em atividades que remontam ao século XVI, notadamente nas cavas de ouro do Jaraguá, SP (Carneiro 2002).

Durante a viagem mencionam-se os conflitos com a mineração e aspectos da ocupação urbana moderna, uma vez que, desde a época do auge da mineração de matérias-primas para indústria cerâmica, na primeira metade do século XX, a região sofreu profundas mudanças, com destaque para a intensa urbanização.
Observa-se marcante cenário da alteração da paisagem pelo Homem, com as modificações drásticas causadas pela urbanização na periferia das grandes cidades. Foram visitados afloramentos de granitos datados do intervalo Neoproterozóico-Cambro-Ordoviciano, além de rochas do Grupo São Roque (Carneiro 1983), que deveriam ajudar os alunos a: (a) reconstruir as condições e ambientes que existiram na época em que elas se formaram e (b) compreender, em primeira aproximação, a idéia de ciclo das rochas que vem sendo desenvolvida nas aulas teórico-práticas. A seqüência de pontos visitados no roteiro compreendera seis pontos de parada, que incluem o Pico do Jaraguá, ponto culminante da cidade de São Paulo. Nos relatórios os alunos apresentam as conclusões de cada grupo. O quadro 3 reproduz as orientações dadas no primeiro ponto da visita.

JAGUARIÚNA A atividade de campo de Ciência do Sistema Terra I, em 2002-2003, dedicou-se ao estudo da história geológica pleistocênica da região de Jaguariúna, realizando-se visita a porto de areia muito menor que o de Itaquaquecetuba (Fig. 3), mas igualmente notável do ponto de vista geológico. Foram estudadas camadas horizontais depositadas em aluviões do rio Camanducaia, além de ações de recuperação de áreas degradadas pela mineração, conduzidas posteriormente ao abandono de algumas cavas. A atividade não voltou 
Quadro 3 - Exemplo de atividades previstas durante a visita a Perus, em 1999.

AFLORAMENTO 1. Pedreira Construcap, próximo à Estrada Velha de Campinas
Neste local encontramos rochas do granito tipo Cantareira. Em alguns locais os megacristais de feldspato são
tão grandes e destacados nos matacões, que a rocha recebe o nome de Granito tipo Olho de Sapo ou Pirituba.
1. Junto com os colegas de seu grupo, procure situar este local no mapa (escala 1:50 000).
2. Procure fazer uma descrição da rocha presente considerando os materiais que conseguir identificar.
3. Aproxime-se do afloramento. Faça um esquema de uma área de cerca de $1 \mathrm{~m}^{2}$ (use o Quadro 1). Seja preciso;
observe e indique a escala. Use uma legenda para indicar os materiais descritos. Na descrição você pode usar os
seguintes critérios: mineralogia, cor, granulação (tamanho dos grãos), textura (feições geométricas de pequenas
dimensões), estruturas e outros critérios que considerar relevantes. Descreva todas as feições tais como: eventual
orientação de minerais na rocha, veios, fraturas, falhas etc.
4. Tendo clareza sobre os materiais presentes, formule hipóteses sobre a gênese das estruturas.
5. Que características são importantes para definir, de um modo geral, os granitos?

a se realizar nos anos subseqüentes, em virtude do esgotamento das reservas e fechamento do porto de areia.

$\mathrm{O}$ porto de areia de Jaguariúna exibe sucessivas camadas com evidências dos processos erosivos e sedimentares relacionados à modificação da paisagem da região de Campinas-Jaguariúna. $\mathrm{Na}$ atividade os alunos foram convidados a reconstruir ambientes existentes na época em que os sedimentos se formaram, com a devida ressalva de que essas condições representam apenas uma breve parte dos processos que atuaram na elaboração da longa história geológica regional.

JACAREÍ Entre 2004 e 2007, a primeira viagem de campo de Ciência do Sistema Terra I foi para Jacareí, em áreas de mineração de areia vizinhas à Rod. Presidente Dutra. Atenção central é dada a alguns experimentos realizados em microcanais de drenagem (Fig. 4) e à história geológica terciária da Bacia de Taubaté. O porto de areia vem sendo progressivamente preenchido pelos rejeitos; as cavas são menores que as de Itaquaquecetuba.

Foram examinadas camadas sedimentares pertencentes ao paleovale do rio Paraíba do Sul, que vêm sendo explotadas há anos. É possível identificar evidências dos processos de erosão e sedimentação originais, e observam-se ainda restos de coberturas de solos e depósitos de turfa que capeiam a planície aluvionar do Rio Paraíba do Sul. As idades da pilha sedimentar pertencem ao Neógeno, entre o Plioceno e o Pleistoceno. $\mathrm{Na}$ atividade a narrativa adotada concentra-se no funcionamento do sistema de classificação (Fig. 5), além de levar os alunos a reconstruir ambientes da época em que os materiais se formaram e compreender uma parte da história geológica da região.

Dentre diversos conceitos importantes a serem assimilados, destacaram-se alguns, essenciais, a serem posteriormente avaliados: escalas de representação, erosão, sedimentos, areia, silte, argila, cascalho, estratificação, camada, transporte e deposição, área-fonte,

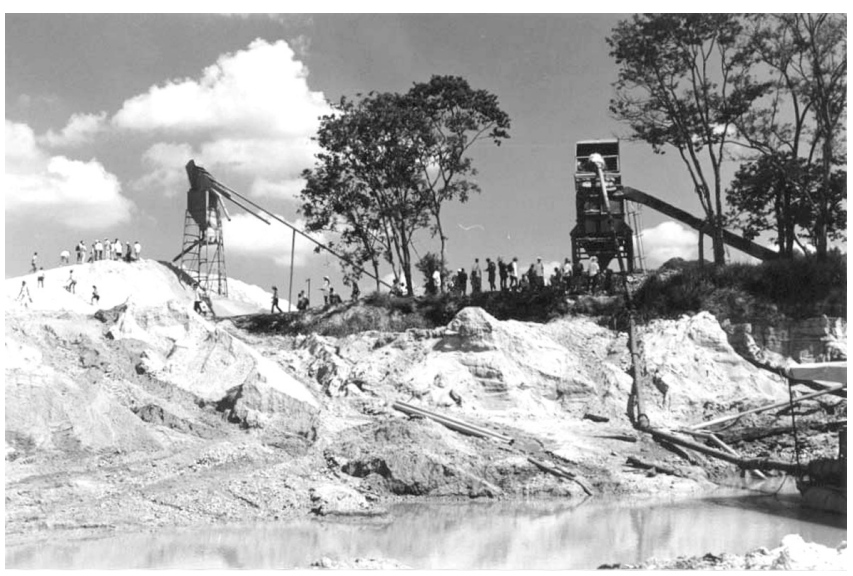

Figura 3 - Acumulação de areias classificadas em Jaguariúna e aspecto da cava, hoje recuperada.

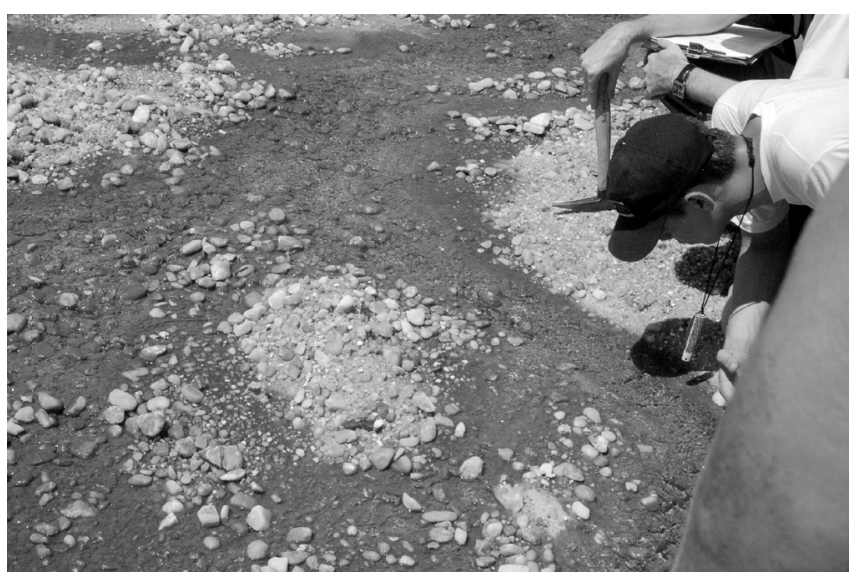

Figura 4 - Experimentos sobre transporte de areias e outras classes granulométricas em Jacareí. 


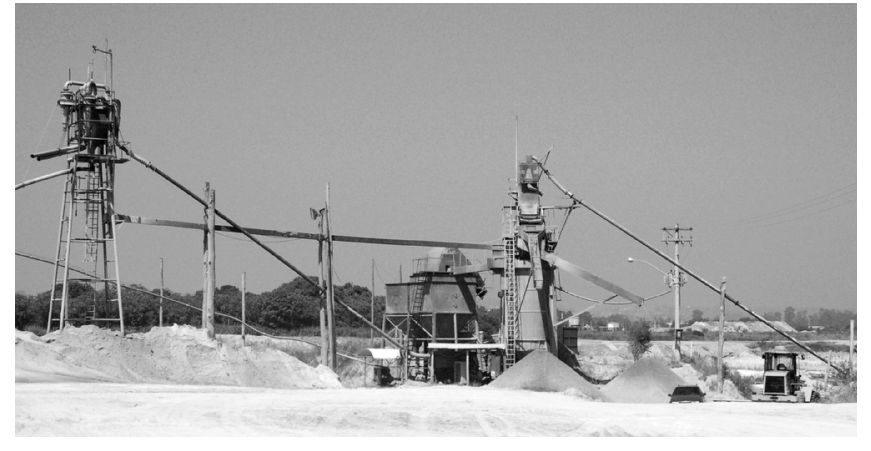

Figura 5 - Instalações de classificação de areia em Jacareí.

energia de transporte, área deposicional, Princípio da Superposição. No quadro 4 apresenta-se inovação oriunda da experiência de 2007, referente à identificação preliminar dos materiais encontrados na forma de seixos. A constituição desses materiais realmente estimula a curiosidade dos estudantes, devendo ser mais bem aproveitada.

Temas tratados em campo $\mathrm{O}$ tema abordado durante as atividades de campo de 1998, "história geológica regional" revelou-se altamente complexo porque, embora os alunos sejam capazes, logo no primeiro momento, de descrever os tipos de rochas encontradas, é prematuro levá-los muito além disso. Mesmo existindo orientação efetiva, é difícil para eles efetuar tarefas tão detalhadas quanto interpretar a relação espacial dos cortes visitados e construir uma história evolutiva regional. As escalas espaciais e temporais envolvidas acham-se além das habilidades de relação e integração de alunos ingressantes.

Quando o professor assume que a função da viagem de campo é somente ilustrar conceitos expostos em sala de aula, os afloramentos passam a ser meros apêndices de uma explanação, ou uma narrativa, previamente desenvolvida. Esse é o tipo mais freqüente de viagem de campo, que Compiani e Carneiro (1993) denominam ilustrativa. Nos demais tipos de papéis didáticos de viagens de campo, motivadora, treinadora, indutiva ou investigativa, pode existir uma dificuldade maior para se atingir os objetivos. Isso requer maior planejamento, e uma gradação de objetivos didáticos: alguns temas são tratados antes de outros, o que equivale a dizer que não se devem lançar os alunos de imediato, em disciplinas geológicas introdutórias, em uma interpretação evolutiva de pontos dispersos com ambientes geológicos e idades muito diversificadas. Dessa forma, construiu-se uma sucessão de etapas que compreendem três temas desenvolvidos nos trabalhos de campo:

- Geologia e sedimentação em portos de areia;

- Glaciação permo-carbonífera;

- Ciclo das Rochas e Tempo Geológico.

Carneiro et al. (2007) assinalam que esse conjunto de temas de campo leva os estudantes a: (a) aplicar e gradualmente construir conhecimentos, ao observar e interpretar processos naturais e produtos geológicos; (b) comparar suas idéias com aquelas formuladas por colegas e professores; (c) compreender, na prática, de que modo a ciência é produzida mediante formulação de teorias, explicações e hipóteses.

GEOLOGIA E SEDIMENTAÇÃO EM PORTOS DE AREIA A primeira atividade desenvolve narrativa baseada na origem de cavas de areia e nos processos atuais de transporte de sedimentos. As cavas aproveitam economicamente sedimentos neogênicos. Os alunos estudam os cortes marginais, o assoalho das escavações e alguns pequenos cursos de água presentes. Os professores procuram orientar um trabalho indutivo, uma vez que as exposições despertam grande interesse dos alunos. O desenrolar da atividade procura estabelecer quais teriam sido os mecanismos naturais que levaram à formação de depósitos arenosos tão amplos. Nas vizinhanças de Campinas são raras e pouco duradouras as extrações de areia. Assim, as localidades visitadas, com exceção de Jaguariúna, são distantes (como Itaquaquecetuba e Jacareí), mas os ótimos resultados justificam

\section{Quadro 4 - Atividades planejadas para futuras visitas ao porto de areia em Jacareí.}

PONTO 3. Cascalhos do Porto de Areia de Jacareí

1. Selecione alguns seixos de tamanhos, formas e cores diferentes para realizar observações.

2. O transporte de seixos numa corrente tende a arredondar os grãos transportados e eles podem se tornar mais esféricos. Defina arredondamento e esfericidade.

3. Descreva as cores, arredondamento, aspereza superficial, e aspecto geral dos seixos que coletou.

4. A maioria dos seixos e cascalhos desse porto de areia é formada pelo mineral quartzo. Quando golpeado com martelo, o quartzo geralmente exibe fratura conchoidal.

5. Muitos seixos possuem minúsculos grãos de quartzo; são pedaços de uma rocha chamada quartzito.

6. É mais raro achar cristais de feldspato, que são coloridos (brancos, róseos ou amarelos) e exibem faces planas.

7. Observando seixos quebrados sob lupa, você consegue distinguir esses três tipos? 
amplamente o longo deslocamento $(150 \mathrm{~km})$.

Os sucessivos experimentos em microcanais de drenagem subsidiam atividades posteriores das disciplinas. Primeiramente, os alunos barram os canais para formar uma represa, em seguida liberam a barreira, para observar o que ocorre com a água e os materiais que carrega. Outra experiência consiste em lançar materiais de distintas granulometrias para observar a deposição progressiva e medir a grosso modo a distância de cada intervalo granulométrico, desde a origem do material, e relacionar a capacidade de transporte de uma corrente com a velocidade do meio - a energia cinética do fluido - e o volume de água presente. Dessa maneira, leis naturais e o funcionamento de fluxos e correntes são construídas qualitativamente a partir de dados discretos.

Carneiro et al. (2007) analisam em pormenores os efeitos dessas investigações e a motivação dos alunos, em sua primeira viagem de campo, causada pelo trabalho "em ambiente ao ar livre, o meter a mão na massa, o trabalho em grupo e a descontração". A baixa expectativa em termos de objetivos facilita muito a aprendizagem, porque proporciona entendimento de interações entre matéria e energia; transformações de materiais; erosão; deposição; reconhecimento de processos e produtos. As experiências capacitam os alunos a interpretar os registros gravados nas paredes das próprias cavas de areia visitadas.

GLACIAÇÃO PERMO-CARBONÍFERA Na segunda atividade são previstas situações em que o aluno deve aplicar noções, conceitos e habilidades desenvolvidos na disciplina, ao tomar contato com rochas do Subgrupo Itararé (Permo-Carbonífero) sobrepostas a rochas do embasamento cristalino. Os alunos aplicam já nesta atividade o conhecimento adquirido na viagem anterior sobre a dinâmica de sedimentos em fluxos aquosos e aplicam o método histórico-comparativo. É grande o salto cognitivo que os alunos experienciam, pois ao comparar dois cortes - um formado por camadas de siltitos e outro de arenitos intercalados com siltitos argilosos - percebem que a granulometria presente nos depósitos sedimentares podem revelar alguns dados essenciais sobre a energia cinética do fluido à época da deposição e, portanto, permitem interpretar paleo-ambientes.

A abordagem praticada em Itu e Salto é indutiva. Nas visitas aos parques naturais, pede-se que os alunos não estudem antecipadamente os painéis que explicam como se desenvolveu a glaciação permo-carbonífera. Eles se sentem instigados a explicar com seus próprios meios como se originou a sucessão rítmica de camadas (Fig. 6). Surge a explicação simples de que a granulometria dos sedimentos é fina em função da baixa energia cinética do fluido, em provável lago ou zona costeira pouco movimentada. Isso é em seguida colocado em dúvida pelos próprios alunos, ao perceberem a existência de calhau e seixos intercalados nas camadas, que se ondulam acima e abaixo deles (Fig. 7). Os alunos são convidados a oferecer explicações alternativas sobre a origem, pois em um meio de baixa energia cinética não é plausível que seixos e calhaus possam ser levados pela corrente até o local.

Quando surge uma hipótese, vacilante, de que eles poderiam ter caído de blocos grandes de gelo nos quais estivessem incrustados e que derreteram progressivamente na água, perdendo a capacidade de sustentálos, alguns alunos espantam-se com a idéia, aparentemente absurda. Ao verem que outros a apóiam, surgem interessantes debates. Ao final, nos painéis expostos, podem conhecer a terminologia adequada a esses processos, e atribuem grande calor ao fato de terem sido eles mesmos os formuladores de um mecanismo que agora passam a denominar "seixos pingados". Pela desenvoltura adquirida, é comum os alunos comentarem: "a segunda excursão foi melhor que a primeira". Com efeito, eles se sentem mais à vontade depois de superar o primeiro contato com o campo (Carneiro et al. 2007).

CICLO DAS ROCHAS E TEMPO GEOLÓGICO A história geológica da região de borda do batólito da Can-

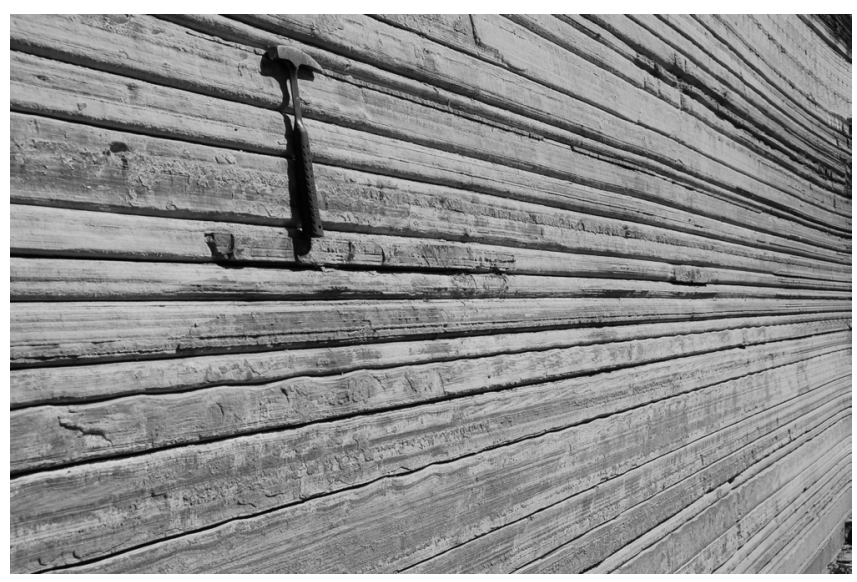

Figura 6 - Alternância de camadas de siltitos e argilitos no parque natural de Itu.

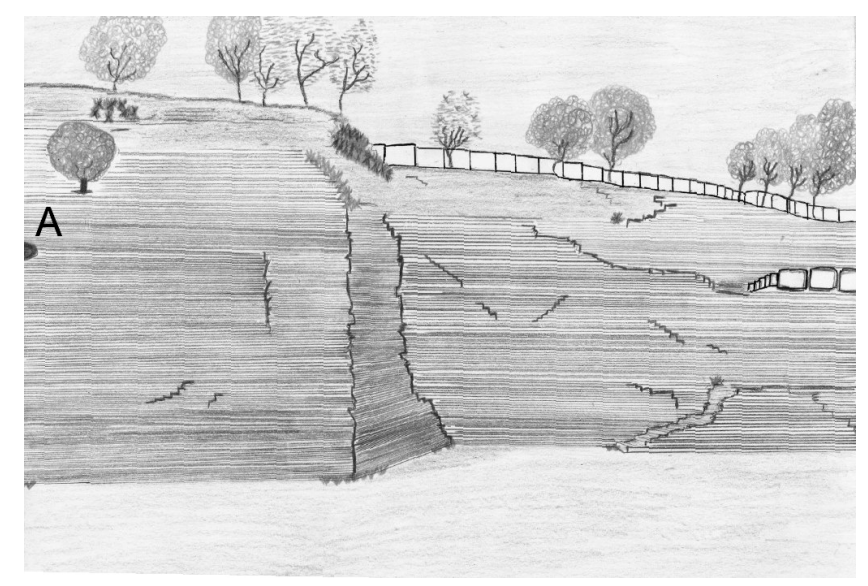

Figura 7 - Representação das paredes do parque em Itu, pelos alunos de 2007 Adriano Rueda, Cibele Lima, Giseli Ramos e Gustavo Melo, com indicação de seixo pingado (A) nas camadas de siltitos e argilitos. 
tareira oferece bons desafios educativos. Em uma área relativamente restrita, as variadas rochas e minerais presentes no Grupo São Roque e nas rochas intrusivas (granitos e pegmatitos) facilitam a reconstrução da seqüência de eventos. As viagens precedentes facilitam o alcance de objetivos mais complexos, como ciclo das rochas e "história geológica regional". Os alunos vinculam os registros a eventos do Neoproterozóico. Um ponto notável é a interação humana com a paisagem, representada por inúmeras intervenções urbanas, rodoviárias e industriais.

Em Perus procurou-se envolver o participante no desenvolvimento de habilidades sistemáticas de pensamento cíclico (Yael e Orion 2000), para que eles fossem capazes de "ler" os processos gravados ("escritos") nas rochas. Permanece o desafio de conceber os estágios "inicial" e "final" dos processos e entender que "cada produto-final de um processo pode ser o pontode-partida para outro processo" (Yael e Orion 2000), tarefa que requer organizar, continuamente, o conhecimento adquirido. São reunidos os indícios e evidências que ajudam a formular o modelo de câmara magmática a partir de diferentes corpos intrusivos e dos contatos com as rochas metamórficas encaixantes - o que inclui o entendimento do metamorfismo regional e de contato.

DISCUSSÃO Os estudantes, nas aulas de campo, são conduzidos a:

(1) Revelar seu conhecimento ao observar e interpretar processos naturais e registros geológicos (Nummer e Carneiro 1998). Os primeiros passos são dados sem ajuda dos professores, de maneira inicialmente motivadora (Compiani e Carneiro 1993), que passa a indutiva em seguida. Isso os leva a explicitar e registrar suas próprias idéias, em um nível de entendimento que pode corresponder à etapa "hipotética" na construção do conhecimento científico (Spencer 1997).

(2) Comparar suas próprias idéias com o conhe- cimento científico sistemático por meio de discussões com colegas e professores. Nessa etapa os alunos precisam mudar suas idéias e adotar a perspectiva científica por meio dessa mediação.

(3) Compreender de modo realista como a ciência realiza suas práticas e elabora teorias, explicações e hipóteses. Trata-se de passos que insistentemente superam o conhecimento por meio de reformulação, debate e complementação. Isso pode ser encontrado na ciência e praticado no ensino, como o revelam Praia (1996) e Sequeiros (1997) ao utilizar a história da ciência no ensino.

CONSIDERAÇÕES FINAIS O trabalho de campo realizado nas disciplinas Ciência do Sistema Terra I e II da Unicamp confirma a visão dominante sobre a relevância do campo no ensino de Geociências. Trabalhos de campo devem estar presentes em todos os estágios que geram o conhecimento, e devem ser planejados como parte integral de um currículo, não como atividade isolada. As duas disciplinas admitem dois tipos de trabalhos de campo, motivador e indutivo, mediante os quais espera-se que o aluno vá aos poucos compreendendo a dinâmica da pesquisa científica ao exercitar certas simulações durante as atividades de campo.

$\mathrm{Na}$ medida em que os alunos são orientados a reorganizar várias vezes o conhecimento adquirido, parece mais fácil formar a idéia de que os estágios inicial e final de processos cíclicos sejam efêmeros, e que pode existir uma conexão entre eles quando o produto-final de um processo pode se transformar no ponto-de-partida de outro.

Agradecimentos Os autores agradecem os comentários de dois revisores da Revista Brasileira de Geociências. Um deles aprovou integralmente a versão original do artigo; o outro fêz sugestões que ajudaram a aprimorar o manuscrito.

\section{Referências}

Almeida F.F.M.de, Riccomini C., Dehira L.K., Campanha G.A.C. 1984. Tectônica da Formação Itaquaquecetuba na Grande São Paulo. In: SBG, Congr. Bras. Geol., 33, Rio de Janeiro, Anais, v. 4, p. 1794-1808.

Almeida F.F.M.de. 1948. A "roche moutonnée" de Salto, Estado de São Paulo. S. Paulo, Geologia e Metalurgia, (5):112-118.

Bach J., Brusi D., Domingo M., Obrador A. 1988. Propuesta de una metodología y jerarquización de las observaciones del trabajo de campo en geología. Univ. Alcalà, Henares, Revista de Geología, 2:319-325.

Carneiro C.D.R. 1983. Análise estrutural do Grupo São Roque na faixa entre o Pico do Jaraguá e a Serra dos Cristais, SP. Tese de doutoramento, Inst. Geoc., USP, São Paulo, 155p.

Carneiro C.D.R. 2002. Cavas de Ouro Históricas do Jaraguá, SP. Os primórdios da mineração no Brasil. In: Schobbenhaus C., Diogenes A. Campos, Emanuel T. Queiroz, Manfredo Winge, Mylène L.C. Berbert-Born.
(Eds.). 2002. Sítios Geológicos e Paleontológicos do Brasil. Brasília: DNPM/CPRM. Comissão Brasileira de Sítios Geológicos e Paleobiológicos (SIGEP). p. 511516.

Carneiro C.D.R., Brito-Neves B.B.de, Amaral I.A.do, Bistrichi C.A. 1994. O Atualismo como princípio metodológico em Tectônica. Bol. Geoc. Petrobrás, 8(2/4):275-293.

Carneiro C.D.R. \& Gonçalves P.W. 2006. Earth System Science Teaching for Geology and Geography Undergraduate Students in Campinas, Brazil. In: IGEO, Intern. Conf. on Geosc. Education, GeoSciEd 5, Baireuth, Germany, Abstracts , p. 60.

Carneiro C.D.R., Gonçalves P.W., Negrão O.B.M., Cunha C.A.L. 2007. Aprendizagem de campo e experiência docente em Ciência do Sistema Terra na Unicamp. In: DGAE/IG/Unicamp, Simpósio de Pesquisa em Ensino e História de Ciências da Terra, 1, e Simpósio Nacional sobre Ensino de Geologia no Brasil, 3, Campinas, 4-8.09.2007, Anais, p. 31-39. (CD-ROM, 069.pdf). 
Carneiro C.D.R., Gonçalves P.W., Negrão, O.B.M., Cunha C.A.L. 2005a. Ciência do Sistema Terra e o entendimento da "máquina" planetária em que vivemos. Geonomos, 13(1):11-18.

Carneiro C.D.R., Mizusaki A.M.P., Almeida F.F.M. de. 2005 b. A determinação da idade das rochas. Terrae Didatica, 1(1):6-35. Disponivel em: http://www.ige.unicamp.br/ terraedidatica/v1n1/t_didatica_2005_v01n01_p006035_carneiro.pdf/.

Carneiro C.D.R., Toledo M.C.M. de, Almeida F.F.M. de. 2004. Dez motivos para a inclusão de temas de Geologia na Educação Básica. Rev. Bras. Geoc. 34(4):553-560.

Coimbra A.M., Riccomini C., Melo M.S. 1983. A Formação Itaquaquecetuba: evidências de tectonismo no quaternário paulista. In: SBG, Simp. Reg. Geol., 4, São Paulo, Atas, p. 253-266.

Compiani M., Carneiro C.D.R. 1993. Os papéis didáticos das excursões geológicas. Rev. de la Enseñanza de las Ciencias de la Tierra. 1(2):90-98.

Cuello Gijón A. 1988. La geología como area interdisciplinar. Henares, Rev. Geol., 2:367-387.

Domingo M., Sequeiros L. 1998. La extinción de la Geologia en España: alerta roja. Rev. de la Enseñanza de las Ciencias de la Tierra, 6(3):206-210.

Earth Science Curriculum Project(ESCP). 1973. Investigando a Terra. v. 1. São Paulo, McGraw-Hill. 435p.

Earth Science Curriculum Project(ESCP). 1976. Investigando a Terra. v. 2. São Paulo, McGraw-Hill. 240p.

Earth Science Curriculum Project(ESCP). 1978. Investigando a Terra. Guia do Professor. São Paulo, McGraw-Hill. (v. 1, 571p.; v. 2, 317p.).

Fyfe W.S. 1997. As ciências da terra e a sociedade: as necessidades para o século XXI. Estudos Avançados, USP, 11(30):175-190.

Gonçalves P.W., Carneiro C.D.R. 2003. Global Science Literacy: from Geology teaching to Earth System Science teaching. In: MAYER, V.J. (ed.) 2003. Implementing Global Science Literacy. Columbus, Ohio: Earth Systems Education Program / The Ohio State Univ. v. 2, p. 203220. (Cap. 14).

Gonçalves P.W., Carneiro C.D.R., Negrão O.B.M., Cunha C.A.L. 2000. Ciência do Sistema Terra e o entendimento da “máquina" planetária em que vivemos. In: International Organization for Science and Teaching Education, Encontro "Perspectivas do Ensino de Biologia", 7, São Paulo, Coletânea, p. 246-248. (Contrib. 2202).

King C. 1990. Earth systems: new interdisciplinarity major looks a problems facing the planet. The Stanford Earth
Scientist, p. 8-12.

Loon A.J. van 1999. The meaning of "abrupteness" in the geological past. Earth Sci. Rev., 45:209-214.

Nummer A.R., Carneiro C.D.R. 1998. The comprehension of space by the study of tectonic structures on different observation scales. In: Intern. Conf. on Geosc. Educ., 2, Hilo, Hawaii, 1997. Conference Proceedings, Ohio, The Ohio State University. p. 160.

Praia J.F. 1996. Epistemologia e historia de la ciencia: contribuciones a la planificación didáctica. La deriva continental. Rev. de la Enseñanza de las Ciencias de la Tierra, 4(1):30-37.

Press F., Siever R., Grotzinger J., Jordan T.H. 2006. Para entender a Terra. 4 ed., Trad. R. Menegat, P.C.D. Fernandes, L.A.D. Fernandes, C.C. Porcher. Porto Alegre, Bookman, $656 \mathrm{p}$.

Rocha-Campos A.C. 2002a. Rocha moutonnée de Salto, SP. Típico registro de abrasão glacial do Neopaleozóico. In: Carlos Schobbenhaus, Diogenes A. Campos, Emanuel T. Queiroz, Manfredo Winge, Mylène L.C. Berbert-Born. (Eds.). 2002. Sítios Geológicos e Paleontológicos do Brasil. Brasília: DNPM/CPRM. Comissão Brasileira de Sítios Geológicos e Paleobiológicos (SIGEP). p. 155160.

Rocha-Campos A.C. 2002b. Varvito de Itu, SP. Registro clássico da glaciação neopaleozóica. In: Carlos Schobbenhaus, Diogenes A. Campos, Emanuel T. Queiroz, Manfredo Winge, Mylène L.C. Berbert-Born. (Eds.). 2002. Sítios Geológicos e Paleontológicos do Brasil. Brasília: DNPM/CPRM. Comissão Brasileira de Sítios Geológicos e Paleobiológicos (SIGEP). p. 147154.

Sequeiros L., Pedrinaci E., Álvarez R.M., Avldivia J. 1997. James Hutton y su teoría de la Tierra (1795): consideraciones para secundaria. Rev. de la Enseñanza de las Ciencias de la Tierra, 5(1):11-20.

Spencer P.K. 1997. The method of multiple working hypotheses in undergraduate education with an example of its application and misapplication. J. Geosc. Educ., 45(2):123-128.

Yael K., Orion N. 2000. Cyclic thinking as applied to the rock cycle. In: GEOSCIED, Intern. Conf. on Geosc. Education, 3, Sidney, Austrália, Abstract Vol., p. 60.

Manuscrito ID 9816

Submetido em 26 de novembro de 2007 Aceito em 20 de junho de 2008 Sistema eletrônico de submissão 